\title{
Sequência didática para o estudo de circuitos elétricos de iluminação
}

\author{
SILVA, Rodolfo Gonçalves Oliveira da ${ }^{1}$ \\ RIBEIRO FILHO, Guido Lessa ${ }^{2}$ \\ FRANCO, Raquel Aparecida Soares Reis ${ }^{3}$
}

\section{RESUMO}

O estudo dos sistemas de iluminação residencial é fundamental para os alunos do curso Técnico em Edificações. Geralmente as práticas de ensino adotadas nas escolas públicas são tradicionalistas, onde o aluno assume uma postura passiva em seu processo de aprendizagem. Este artigo avalia a contribuição de uma sequência didática sobre circuitos elétricos de iluminação residencial, acionados por interruptores simples, intermediários e paralelos no Curso Técnico Integrado em Edificações. $O$ trabalho proposto foi concebido para que pudesse contribuir com o docente no processo de ensino, a fim de motivar no aluno a consciência, a motivação, a reflexão e o prazer pelo estudo. Para tanto, utilizouse ambientes virtuais de aprendizagem combinadas com o uso de componentes animados, além de aulas práticas laboratoriais. Os resultados demonstraram que o uso de sequências didáticas, quando bem planejadas, torna o processo de ensino-aprendizagem mais dinâmico, interativo e mais eficiente.

Sequência Didática. Circuito Elétrico. Aprendizagem.

\section{Didactic sequence for the study of electrical lighting circuits}

\section{ABSTRACT}

The study of residential lighting systems is essential for students of the Technical Course in Buildings. Generally the teaching practices adopted in public schools are traditionalist, where the student takes a passive stance in his learning process. This article evaluates the contribution of a didactic sequence on electrical circuits of residential lighting, activated by simple, intermediate and

\footnotetext{
${ }^{1}$ Doutor em Geotecnia de Pavimentos pela UFOP. Professor do Instituto Federal de Minas Gerais (IFMG) - Campus Congonhas. Departamento da Área de Edificações. Email: rodolfo.goncalves@ifmg.edu.br. Lattes: http://lattes.cnpq.br/3800171772037730. Orcid: https://orcid.org/0000-0001-6505-1392

${ }^{2}$ Mestre em Construção Metálica pela UFOP. Professor do Instituto Federal de Minas Gerais (IFMG) - Campus Congonhas. Departamento da Área de Edificações. Email: guido.lessa@ifmg.edu.br. Lattes: http://lattes.cnpq.br/6855090756693766. Orcid: https://orcid.org/0000-0001-8405-2550.

${ }^{3}$ Doutora em Educação pela linha de pesquisa Educação e Linguagem da Faculdade de Educação da UFMG. Professora do Instituto Federal de Minas Gerais (IFMG). Email: raquel.franco@ifmg.edu.br. Lattes: http://lattes.cnpq.br/6780119064688787. Orcid: https://orcid.org/0000-0001-8308-3611.
} 
parallel switches in the Integrated Technical Course in Buildings. The proposed work was conceived so that it could contribute with the teacher in the teaching process, in order to motivate in the student the conscience, the motivation, the reflection and the pleasure for the study. For that, virtual learning environments were used combined with the use of animated components, in addition to practical laboratory classes. The results showed that the use of didactic sequences, when well planned, makes the teaching-learning process more dynamic, interactive and more efficient.

Didactic Sequence. Electrical Circuits. Learning.

\section{Secuencia Didáctica para el Estudio de Circuitos Eléctricos de Iluminación}

\section{RESUMEN}

El estudio de los sistemas de iluminación residencial es esencial para los estudiantes del Curso Técnico en Edificaciones. En general, las prácticas docentes adoptadas en las escuelas públicas son tradicionalistas, donde el alumno adopta una postura pasiva en su proceso de aprendizaje. Este artículo evalúa la contribución de una secuencia didáctica en circuitos eléctricos de iluminación residencial, activada por interruptores simples, intermedios y paralelos en el Curso Técnico Integrado en Edificaciones. El trabajo propuesto fue concebido para que pueda contribuir con el profesor en el proceso de enseñanza, con el fin de motivar en el alumno la conciencia, la motivación, la reflexión y el placer por el estudio. Para ello, se utilizaron ambientes virtuales de aprendizaje combinados con el uso de componentes animados, además de clases prácticas de laboratorio. Los resultados mostraron que el uso de secuencias didácticas, cuando bien planeadas, hace que el proceso de enseñanza-aprendizaje sea más dinámico, interactivo y más eficiente.

\section{Secuencia Didáctica. Circuito Eléctrico. Aprendizaje.}

\section{Sequenza didattica per lo studio dei circuiti di illuminazione elettrica}

\section{RIASSUNTO}

Lo studio dei sistemi di illuminazione residenziale è essenziale per gli studenti del Corso tecnico in edifici. Generalmente le pratiche di insegnamento adottate nelle scuole pubbliche sono tradizionaliste, in cui lo studente assume una posizione passiva nel suo processo di apprendimento. Questo articolo valuta il contributo di una sequenza didattica sui circuiti elettrici di illuminazione residenziale, attivati da interruttori semplici, intermedi e paralleli nel Corso tecnico integrato negli edifici. II lavoro proposto è stato concepito in modo da poter contribuire con l'insegnante nel processo di insegnamento, al fine di motivare nello studente la coscienza, la motivazione, la riflessione e il piacere per lo studio. A tale scopo, sono stati utilizzati ambienti di apprendimento virtuale combinati con l'uso di componenti animati, oltre a lezioni pratiche di laboratorio. I risultati

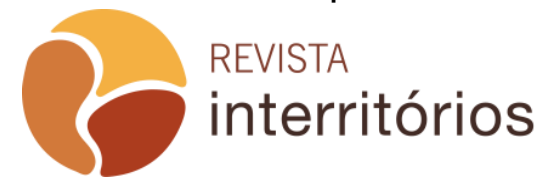


hanno mostrato che l'uso di sequenze didattiche, se ben pianificato, rende il processo di insegnamento-apprendimento più dinamico, interattivo ed efficiente.

\section{Sequenza Didattica. Circuito Elettrico. Apprendimento.}

\section{INTRODUÇÃO}

O estudo dos circuitos elétricos é fundamental na formação de Técnicos em Edificações, de maneira a habilitá-los no desenvolvimento e interpretação de projetos de instalações elétricas de edificações residenciais e comerciais. Para uma melhor compreensão destes conteúdos, os alunos necessitam de conhecimentos prévios adquiridos na disciplina de Física. Nesta etapa do curso de Edificações, os circuitos são facilmente compreendidos pelos alunos. No entanto, os mesmos normalmente encontram dificuldade para formular os modelos mentais das ligações dos interruptores que comandam esses circuitos: interruptores simples, interruptores paralelos e interruptores intermediários, em particular no caso dos dois últimos tipos.

Acreditando que a adoção de uma sequência didática (SD), quando bem planejada, pode contribuir com a assimilação do conhecimento pelos alunos é que se utilizou a metodologia de ensino apresentada neste trabalho. Espera-se que esta proposta metodológica contribua com o docente no processo de ensino, a fim de motivar e despertar no aluno o senso crítico, a reflexão e a motivação pelo estudo. Neste sentido, este artigo objetiva avaliar a contribuição de uma sequência didática sobre circuitos elétricos de iluminação residencial, acionados por interruptores simples, intermediários e paralelos no Curso Técnico Integrado em Edificações.

Partindo desse objetivo, entende-se que uma sequência didática (SD) seja eficiente é necessário que ela seja adaptada ao estilo de aprendizagem predominante dos sujeitos da pesquisa. Uma pesquisa conduzida por Pereira e Vieira (2013) apontou que a maioria dos alunos do ensino médio são predominantemente sensoriais, visuais, ativos e sequenciais. Ou seja, se lembram melhor daquilo que veem por imagens e demonstrações, possuem raciocínio linear e gostam de tentar fazer as coisas por si próprios (FELDER; SILVERMAN, 1988). Deve-se ressaltar que as metodologias de ensino empregadas no ensino de projetos elétricos residenciais devem promover 0 senso crítico, a reflexão e a motivação pelo estudo.

Vários autores afirmam a necessidade da atualização e do uso de tecnologias no ensino, que busquem uma prática pedagógica voltada para um aprendizado mais significativo, perante a crescente insatisfação com 0 paradigma tradicional de ensino ainda dominante nas escolas. Além disso, quando essas tecnologias educacionais são utilizadas sem planejamento prévio, podem gerar insucessos (COVOLAN; SILVA, 2005; VIEIRA JÚNIOR, 2012). 
Schmeck (1988) destaca que o aprendizado se torna mais eficaz quando há concordância entre os estilos dos professores e alunos.

Júnior e Colvara (2010) concluem seu trabalho enfatizando que as avaliações tradicionais podem não mensurar o aprendizado conceitual dos alunos, visto que o sistema de crenças dos professores pode influenciar o modo pelo qual eles avaliam. Além disso, recomenda-se a aplicação de avaliações mais bem elaboradas, levando em consideração as habilidades que efetivamente mensurem o aprendizado do aluno, o que contribuirá para a educação cognitiva ganhar espaço relevante nos procedimentos escolares. Neste sentido, diversificar os métodos pedagógicos, tais como: a utilização de sequências didáticas e a elaboração de novos modelos de avaliação da aprendizagem torna-se atrativo do ponto de vista educacional.

Neste contexto, a utilização de ambientes virtuais de aprendizagem combinados com 0 uso de componentes animados podem contribuir efetivamente com o processo de ensino/aprendizagem. $\mathrm{Na}$ atualidade, os estudantes costumam ter acesso rápido a informação, utilizando intensamente os computadores, smartphones, internet e redes sociais. Segundo Borges e Silva (2013, p. 4), eles fazem parte da geração $Z$, definida como as pessoas nascidas nos últimos anos, emergidas na era digital, que são dependentes da tecnologia para a compreensão do mundo. De acordo com Lopes et al. (2016), vários estudos apontam que a intimidade dos jovens com as ferramentas digitais se apresenta como um facilitador do processo de inserção das ferramentas no ensino, além de formar egressos mais preparados para o mercado de trabalho.

Diante do exposto, a sequência didática proposta neste estudo foi concebida para contribuir com o docente, no processo de ensino dos circuitos elétricos residenciais, no sentido de motivar os alunos a explorar, questionar e pensar sobre o funcionamento de um sistema típico de iluminação residencial.

\section{Sequências Didáticas}

Vivemos numa época em que o processo de educar é extremamente desafiador, visto que as metodologias de ensino adotadas durante muito tempo não produzem efetivamente o mesmo impacto nos alunos se comparados às gerações anteriores. O grande desafio do professor é fazer com que o conhecimento transmitido faça sentido prático na vida dos seus alunos, uma vez que podem apresentar dispersos e desinteressados se o tema abordado na aula for estranho ou alheio à sua realidade existencial.

Em geral, as práticas de ensino adotadas nas escolas são tradicionalistas, com ênfase na tríade definição, exemplo e exercício. Outro ponto importante a se destacar é a relação professor-aluno de caráter essencialmente narrativo 
observado por Freire (1987), onde o professor assume o papel de narrador e os alunos como sendo o objeto passivo que escuta. Ou seja, o docente é aquele que "deposita" o conteúdo da narração e os alunos são os "depósitos", que caracteriza o que ele chamou de concepção bancária da educação, um processo técnico e mecânico de transferência de conhecimentos. Através da educação, Paulo Freire propõe o combate a alienação do sujeito perante o mundo em que vive. No contexto educacional, educador e educando, são os dois seres criadores que libertam mutuamente para chegarem a ser, ambos, criadores de novas realidades.

O processo de ensino-aprendizagem é complexo em sua natureza, uma vez que as relações humanas são estruturadas na subjetividade das interações sociais e na capacidade de comunicação entre os humanos. Dentro deste contexto, Cabral (2017) enfatiza a necessidade de diversificar propostas metodológicas alternativas, de forma que o aluno abandone a postura passiva intensificada pelo modelo tradicional de ensino e adote uma postura mais participativa e ativa, tornando-se protagonista no seu processo de aprendizagem. O professor deve assumir uma conduta de provocador e organizador de ideias. Para isso, o professor deve lançar mão de recursos didáticos que poderão auxiliá-lo no dia a dia da sala de aula. Um desses recursos é a sequência didática.

As chamadas "sequências didáticas" são propostas metodológicas para a organização e planejamento do ensino, e cujo desenvolvimento busca melhorar a qualidade da educação oferecida aos alunos. Importantes trabalhos foram desenvolvidos internacionalmente, liderados por um grupo de pesquisadores de Genebra, tais como Joaquim Dolz, Sylvie Haller, Jean-Paul Bronckart, Bernard Schneuwly e A. Pasquier. Essas produções científicas tinham ênfase nas sequências didáticas que foram aplicadas no campo da aprendizagem da língua francesa no sentido de minimizar as dificuldades recorrentes da produção da língua escrita (CABRAL, 2017).

Zabala (1998) afirma que um conhecimento mais profundo das variáveis que influenciam no processo de aprendizagem dos alunos permitem introduzir nas diferentes formas de intervenção aquelas atividades que possibilitem uma atuação mais satisfatória dos professores nas aulas. Para este autor, uma sequência didática pode ser entendida como

[...] um conjunto de atividades ordenadas, estruturadas e articuladas para a realização de certos objetivos educacionais, que tem um princípio e um fim conhecidos tanto pelos professores como pelos alunos. (ZABALA, 1998, p.18).

Nesta perspectiva, a sequência didática pode contribuir para melhorar a atuação docente nas aulas, principalmente nas escolas públicas. Para tanto, é necessário que o Estado desenvolva políticas públicas que estimule sua difusão 
e aplicação. A partir de 1997, o Brasil começa a trabalhar a concepção de sequências didáticas com a publicação dos Parâmetros Curriculares Nacionais, quando aborda o tratamento didático dos conteúdos de língua Portuguesa explorando a noção de "atividades sequenciadas de leitura", sendo:

\begin{abstract}
São situações didáticas adequadas para promover o gosto de ler e privilegiadas para desenvolver o comportamento do leitor, ou seja, atitudes e procedimentos que os leitores assíduos desenvolvem a partir da prática de leitura [...] Funcionam de forma parecida com os projetos - e podem integrá-los, inclusive -, mas não têm um produto final determinado: neste caso o objetivo explícito é a leitura em si. Nas atividades sequenciadas de leitura pode-se, temporariamente, eleger um gênero específico, um determinado autor ou um tema de interesse. (BRASIL, 1997, p. 46).
\end{abstract}

Cabral (2017) enfatiza que embora estejam especificamente vinculadas ao ensino dos gêneros textuais em sala de aula, tais proposições podem ser adaptadas e utilizadas em diversos contextos de aprendizagem e, portanto, ligadas a diferentes objetos de conhecimento. $O$ uso de sequência didática para o ensino e a aprendizagem dos gêneros escritos e orais ganhou mais destaque no Brasil com a publicação do trabalho de Dolz e colaboradores em 2004 (DOLZ; NOVERRAZ; SCHNEUWLY, 2004).

Segundo estes autores o procedimento metodológico de sequência didática é por definição

Um conjunto de atividades escolares organizadas, de maneira sistemática, em torno de um gênero oral ou escrito, [...] com a finalidade de ajudar o aluno a dominar melhor um gênero de texto, permitindo-lhe, assim, escrever ou falar de maneira mais adequada numa dada situação de comunicação. (DOLZ; NOVERRAZ; SCHNEUWLY, 2004, p. 97).

Nessa concepção da escola de Genebra, DOLZ, et al. (2004, p. 98) apresentam alguns passos denominados de esquema da SD, constituída por quatro etapas:

- Apresentação da situação: etapa que serão escolhidos o contexto, a forma e conteúdo do gênero a ser estudado e produzido;

- Produção inicial: esta etapa é fundamental para que o professor possa compreender o quanto os alunos sabem sobre o gênero objeto de ensino, identificar os problemas linguísticos do gênero que deverão ser enfocados e definir as ações de ensino posteriores que serão trabalhadas para atingir os objetivos de aprendizagem. É a fase diagnóstica dos sujeitos;

- Módulos: Cada módulo é composto de atividades relativas ao desenvolvimento das capacidades de linguagem a fim de garantir melhora 
dos alunos na compreensão e uso da expressão oral ou escrita estudada. A quantidade e conteúdo dos módulos de ensino devem ser definidos de acordo com as informações colhidas pelo professor da primeira produção dos alunos;

- Produção final: nesta fase os alunos devem colocar em prática o domínio adquirido ao longo da aprendizagem acerca do gênero e do tema propostos e permitirá ao professor avaliar o trabalho desenvolvido. Esta fase permitirá aferir se a SD foi eficiente para atingir os objetivos propostos.

Segundo Oliveira (2013, apud BATISTA et al., 2016, p. 5382), uma SD deve ser estruturada a partir da escolha do tema a ser trabalhado; questionamento para problematização do assunto a ser trabalhado; planejamento dos conteúdos; objetivos a serem atingidos no processo de ensino-aprendizagem e delimitação da sequência de atividades. De acordo com a referida autora, SD pode ser definida como um simples procedimento composto por um conjunto de atividades interligadas, e necessita de um planejamento prévio para delimitação de cada etapa e/ou atividade, tornando o processo de ensino-aprendizagem mais dinâmico.

Tomando como referência os conceitos da SD, no próximo tópico trataremos sobre os conceitos de corrente elétrica e interruptores de luz, pois um dos objetivos deste trabalho é apresentar uma metodologia de ensino para a aprendizagem do sistema de iluminação de uma edificação.

\section{Conceito de Circuito Elétrico}

$\mathrm{Na}$ atualidade, é senso comum de que a carga elétrica pode deslocar-se de um lado para outro pelo movimento de elétrons ou de portadores de carga elétrica, como os íons. Nos meios sólidos, o transporte de cargas ocorre pelo deslocamento dos próprios elétrons, mas nos meios fluidos ou gasosos, há o deslocamento de íons, elétrons ou de ambos simultaneamente. Procura-se utilizar meios sólidos em produtos destinados a aplicações em eletricidade, principalmente os metais, que são bons condutores de corrente elétrica, e são utilizados preferencialmente utilizados na fabricação de fios, cabos e placas metálicas, em especial o cobre, por ser este metal um dos melhores condutores de eletricidade. (VÁLIO; FUKUI, et al., 2016).

No cobre, uma parcela dos elétrons orbita livre e aleatoriamente entre os átomos vizinhos, em uma situação resultante de equilíbrio, pois não há deslocamento médio do coletivo dos elétrons. Este metal, quando sujeito a uma diferença de potencial (DDP) existente entre dois polos de uma fonte de energia, surge um campo elétrico e uma força elétrica que age sobre os elétrons. Esta força tem mesma direção do campo elétrico criado pela DDP, mas os elétrons passam a movimentar-se ordenadamente em sentido contrário à força, pois 
possuem carga negativa, movimento este, denominado de corrente elétrica. (LARA, 2016).

Os circuitos elétricos são compostos por fonte de alimentação, conjunto de equipamentos, condutores, e dispositivos de proteção e/ou interruptores. A finalidade dos circuitos é prover alimentação elétrica para o funcionamento de um equipamento/aparelho elétrico. Tais sistemas necessitam de comandos "ligar" e "desligar", conforme a necessidade, e para isso são instalados os interruptores, que podem ser de três tipos:

- Interruptor simples: estes componentes do circuito elétrico interrompem o condutor fase de onde comanda-se o equipamento (liga/desliga);

- Interruptor paralelo (three-way): interruptores que operam sempre em dupla com outro interruptor paralelo, neste caso, ambos trabalham como desviadores da corrente elétrica entre dois subcircuitos associados a eles (NISKIER; MACINTYRE, 2016).

- Interruptor intermediário (four-way): são interruptores que operam entre dois interruptores paralelos, atuando como desviadores da corrente elétrica para quatro subcircuitos associados a eles. (NISKIER; MACINTYRE, 2016).

O conhecimento do circuito elétrico é fundamental na formação do aluno, sendo fundamental na concepção, desenvolvimento e interpretação de projetos de instalações elétricas de edificações residenciais e comerciais, respeitando-se os limites regulamentados para o Técnico em Edificações. Facilitando a interpretação e aplicação das exigências normativas que regem as instalações elétricas em baixa tensão, impostas pela Associação Brasileira de Normas Técnicas (ABNT), pela Companhia Energética de Minas Gerais (CEMIG) e por outros órgãos de normalização com abrangência nacional e internacional. Consequentemente, este conhecimento auxilia-o na pesquisa, identificação e escolha correta dos materiais disponíveis no mercado e empregados nas instalações elétricas de edificações. Bem como elaborar estimativas de materiais e realizar orçamentos referentes ao projeto e à execução das instalações elétricas de edificações.

A seguir, será apresentada a metodologia pedagógica desenvolvida e aplicada, indicando as etapas desenvolvidas na SD de forma a possibilitar o ensino do tema proposto aos alunos participantes deste estudo.

\section{Metodologia}

O presente trabalho foi desenvolvido no campus do IFMG, localizado no município de Congonhas. Devido à dinâmica escolar só foi possível a participação de uma turma na pesquisa, com alunos do $2^{\circ}$ ano, modalidade 
integrado, do curso Técnico em Edificações. Inicialmente o grupo de avaliação era composto por 35 alunos, mas no decorrer da pesquisa alguns alunos deixaram de participar de algumas das etapas. Portanto, os resultados aqui apresentados são referentes somente aos alunos que participaram de todas as fases da pesquisa, neste caso, foram selecionados os resultados obtidos por 18 alunos.

Com base nas informações socioeconômicas informadas na matrícula, foram obtidos os resultados apresentados nos Gráficos 1, 2 e 3, referentes respectivamente à renda familiar, cor da pele e instituição de ensino onde cursou o Ensino Fundamental. A maior parcela dos alunos pesquisados pertence ao grupo com renda familiar entre um a três salários mínimos, declarados brancos e que concluíram o ensino fundamental em escolas públicas.

O IFMG - Campus Congonhas atende alunos de Congonhas e regiões limítrofes, como os municípios de Ouro Branco e Conselheiro Lafaiete. Inicialmente foi apresentado aos alunos o objetivo desta pesquisa e as etapas de desenvolvimento da mesma. A sala de aula conta com um projetor multimídia e quadro branco escolar. O Laboratório de Informática é composto por 40 (quarenta) computadores ligados em rede e uma lousa digital interativa.

\section{Gráfico 1 - Renda Familiar dos alunos}

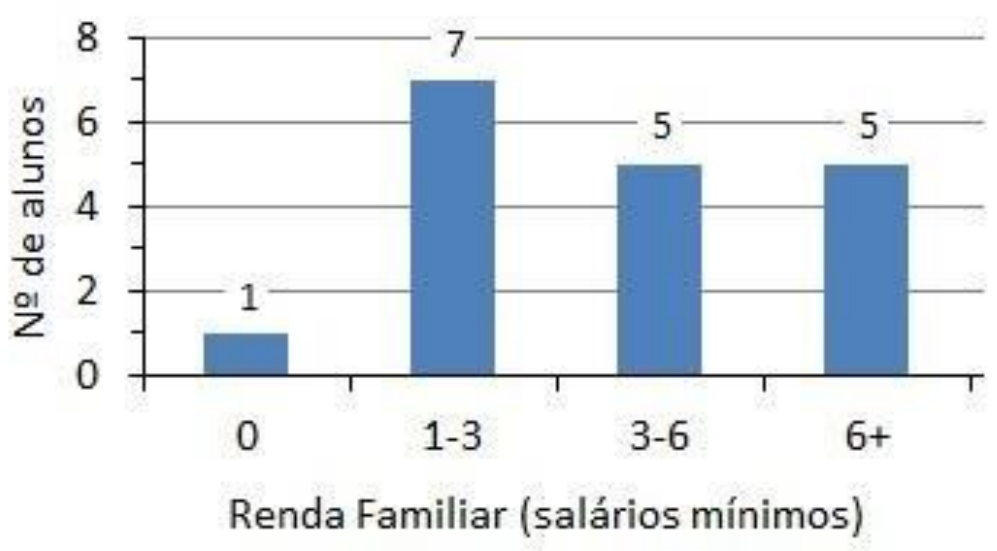

Fonte: O autor (2020). 
Gráfico 2 - Cor da pele declarada pelos alunos

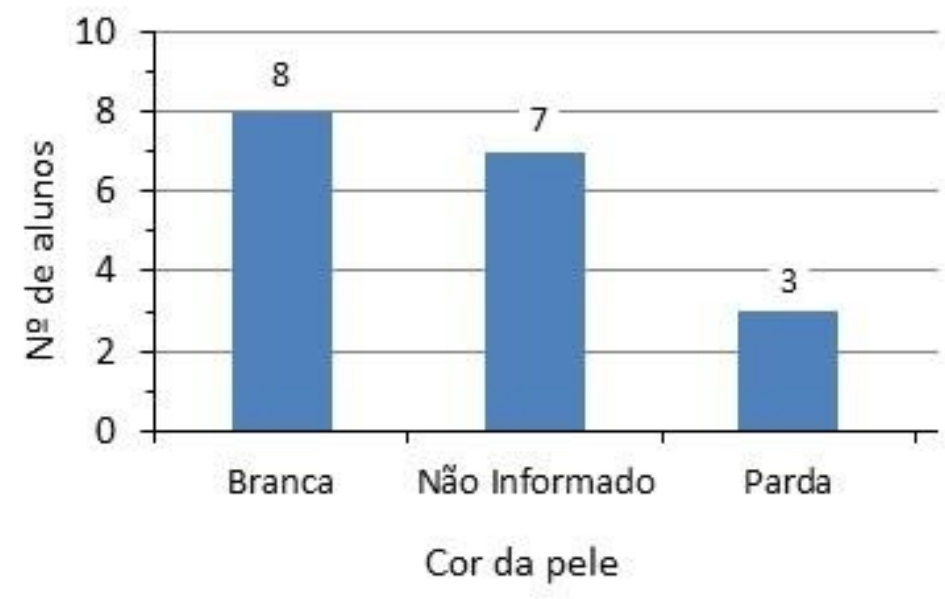

Fonte: O autor (2020).

Gráfico 3 - Instituição de ensino onde os alunos cursaram o ensino fundamental

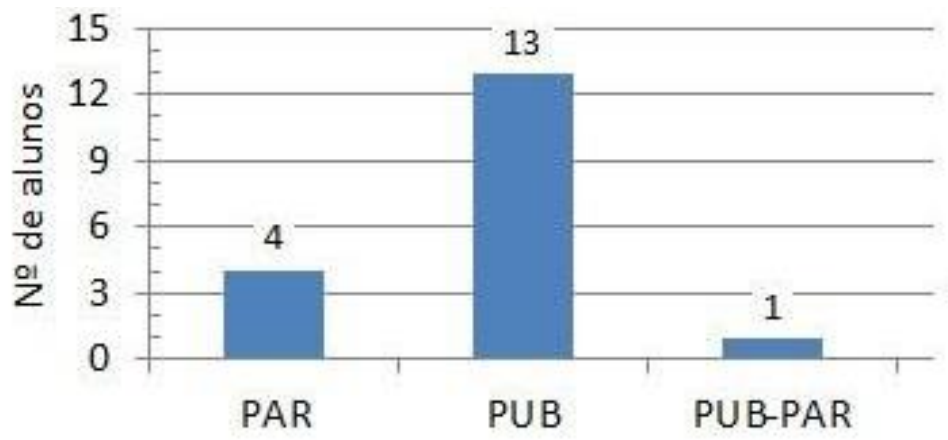

Fonte: O autor (2020).

Tipo de instituição de ensino

As etapas de desenvolvimento do produto educacional proposto foram divididas em três etapas (Quadro 1), de forma a motivar o aluno na compreensão dos circuitos elétricos residenciais utilizando interruptores simples, paralelos e intermediários. A primeira e última etapa foram concebidas de forma a avaliar a eficácia da sequência didática aplicada, bem como a percepção do aluno durante o processo de aprendizagem.

Quadro 1 - Etapas de desenvolvimento do produto educacional

\begin{tabular}{|c|c|c|}
\hline Etapa & Identificação & Conteúdo \\
\hline $1^{\underline{a}}$ & Pré-sequência didática & Avaliação Diagnóstica \\
\hline $2^{\underline{a}}$ & Sequência Didática (SD) & Aulas sequenciadas \\
\hline $3^{\text {a }}$ & Pós-sequência didática & $\begin{array}{c}\text { Avaliação Diagnóstica } \\
\text { Entrevista Semiestruturada }\end{array}$ \\
\hline
\end{tabular}

Fonte: O autor (2020). 
A primeira etapa contemplou a realização de uma avaliação diagnóstica, denominada "Teste 1", composta de dez questões relacionadas à circuitos elétricos, que tinha como objetivo testar o conhecimento prévio do aluno sobre sistema de iluminação residencial com utilização de interruptores simples, paralelos e intermediários. Vale ressaltar que uma aluna era portadora de surdez congênita, de modo que este teste foi elaborado para ser bastante ilustrativo, com muitas figuras e imagens, a fim de facilitar a realização do mesmo pela aluna. Durante todas as fases da pesquisa ela também foi auxiliada por um intérprete de libras. A segunda etapa foi composta pela SD, que foi estruturada em cinco aulas apresentadas no Quadro 2. As atividades descritas nesta etapa foram elaboradas utilizando variadas ferramentas pedagógicas para que o processo de aprendizagem fosse mais dinâmico e atrativo aos alunos.

Quadro 2 - Estrutura da sequência didática utilizada nesta pesquisa

\begin{tabular}{|c|l|c|}
\hline Aula & \multicolumn{1}{|c|}{ Atividade } & $\begin{array}{c}\text { Duração } \\
\text { da aula }\end{array}$ \\
\hline 1 & $\begin{array}{l}\text { Baseia-se na aula expositiva tradicional, cujo conteúdo abordado se } \\
\text { refere a: circuito elétrico de iluminação residencial utilizando } \\
\text { interruptores simples, paralelos e intermediários. }\end{array}$ & $\begin{array}{c}100 \\
\text { minutos }\end{array}$ \\
\hline 2 & $\begin{array}{l}\text { Apresentação do software PhET aos alunos. No Laboratório de } \\
\text { Informática do IFMG, os alunos foram orientados a construir } \\
\text { virtualmente um circuito elétrico com um interruptor simples, usando } \\
\text { a ferramenta online denominada "Kit para montar Circuito DC", } \\
\text { disponibilizada gratuitamente pela University of Colorado Boulder. }\end{array}$ & $\begin{array}{c}50 \\
\text { minutos }\end{array}$ \\
\hline 3 & $\begin{array}{l}\text { Aplicação de uma atividade avaliativa denominada "Teste 2", em que } \\
\text { os alunos tiveram que montar virtualmente no PhET os diagramas } \\
\text { representativos de circuitos elétricos de iluminação residencial com } \\
\text { interruptores simples. }\end{array}$ & $\begin{array}{c}50 \\
\text { minutos }\end{array}$ \\
\hline 4 & $\begin{array}{l}\text { Uso de componentes animados para explicar o funcionamento dos } \\
\text { interruptores paralelos e intermediários no circuito elétrico de } \\
\text { iluminação residencial. }\end{array}$ & $\begin{array}{c}50 \\
\text { minutos }\end{array}$ \\
\hline 5 & $\begin{array}{l}\text { Aplicação de uma atividade prática que avaliou a capacidade do } \\
\text { aluno em montar, no Laboratório de Instalações Elétricas, circuitos } \\
\text { elétricos de iluminação residencial utilizando os interruptores } \\
\text { simples, paralelos e intermediários. }\end{array}$ & $\begin{array}{c}100 \\
\text { minutos }\end{array}$ \\
\hline
\end{tabular}

Fonte: O autor (2020).

$\mathrm{Na}$ terceira etapa foi realizada novamente a avaliação diagnóstica aplicada no teste inicial, neste caso denominado "Teste 3", para avaliar se houve aprendizagem e assimilação do conteúdo abordado pelo aluno após a SD. Também foi realizada uma entrevista semiestruturada, como forma de melhor compreender a percepção do aluno sobre a SD utilizada, retratar as dificuldades encontradas e apontar pontos positivos e negativos sobre a metodologia adotada. De acordo com Moreira (1997), a análise de protocolos, o uso de 
informações verbais do sujeito como fonte de dados tem sido a técnica mais usada para investigar a cognição humana.

A avaliação diagnóstica inicial, denominada "Teste 1", teve pontuação máxima de 10 pontos e foi composta por 23 itens avaliativos, todos com o mesmo valor. Ela tinha como objetivo principal avaliar o conhecimento prévio do aluno referente à corrente elétrica e sistema de iluminação residencial. Após a aplicação da SD, esta mesma avaliação foi aplicada novamente, agora denominada "Teste 3", cujo objetivo foi avaliar a progressão do aluno na compreensão do tema.

No ambiente virtual do PhET, mostrado na Figura 1, os alunos foram submetidos a uma avaliação denominada "Teste 2", que consiste na montagem de dois circuitos elétricos, um em série e outro em paralelo, apresentados na Figura 2. O objetivo do teste foi proporcionar ao aluno a oportunidade de observar o circuito em funcionamento e a movimentação dos elétrons nos condutores. Este software permite aos alunos selecionar os componentes do circuito elétrico para montagem e realizar medições de parâmetros físicos do sistema, tais como intensidade da corrente elétrica que passa no condutor.

Figura 1 - Plataforma do PhET

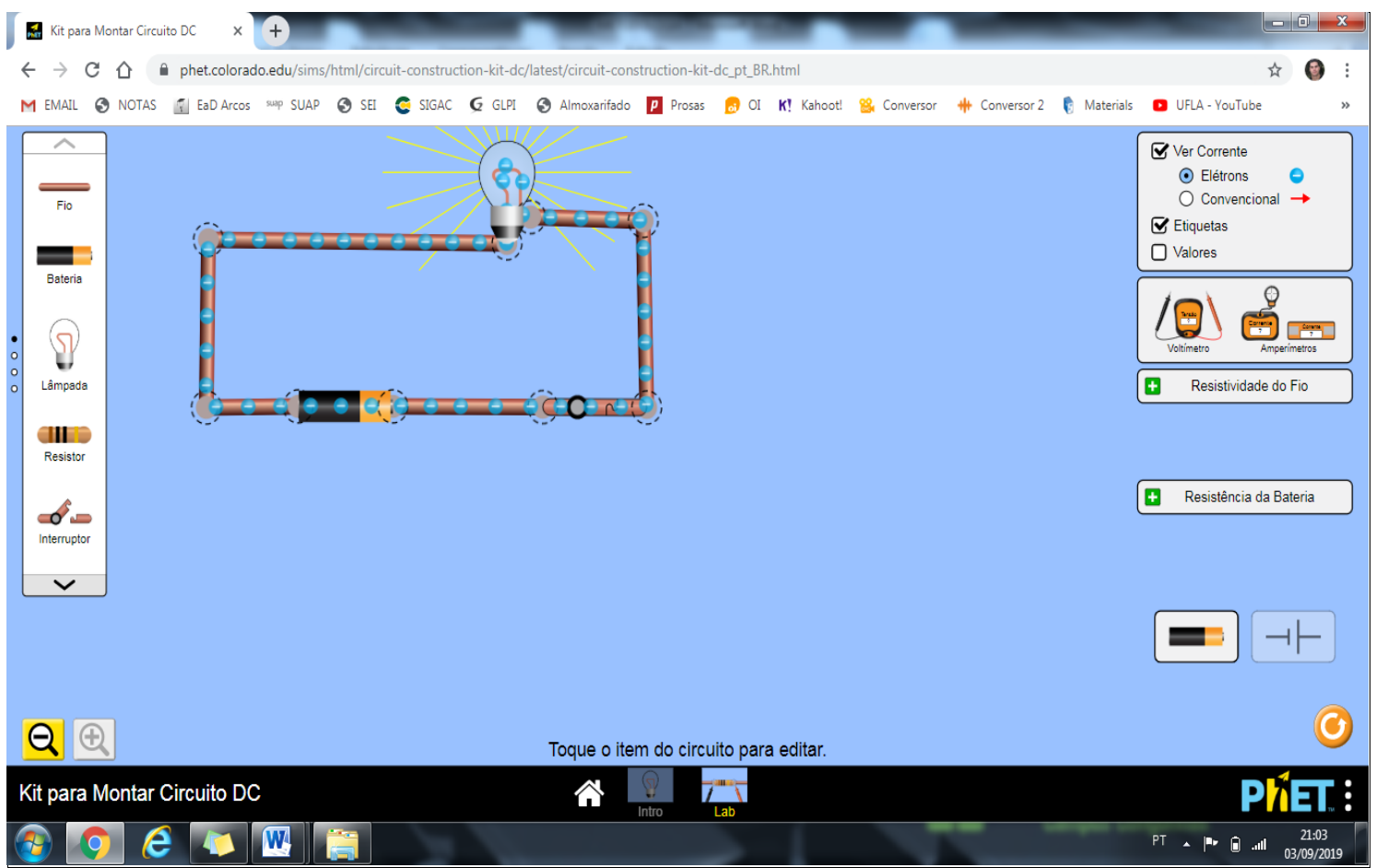

Fonte: https://phet.colorado.edu/sims/html/circuit-construction-kit-dc/latest/circuit-constructionkit-dc_pt_BR.html. 
Figura 2 - Circuito elétricos utilizados no Teste 2
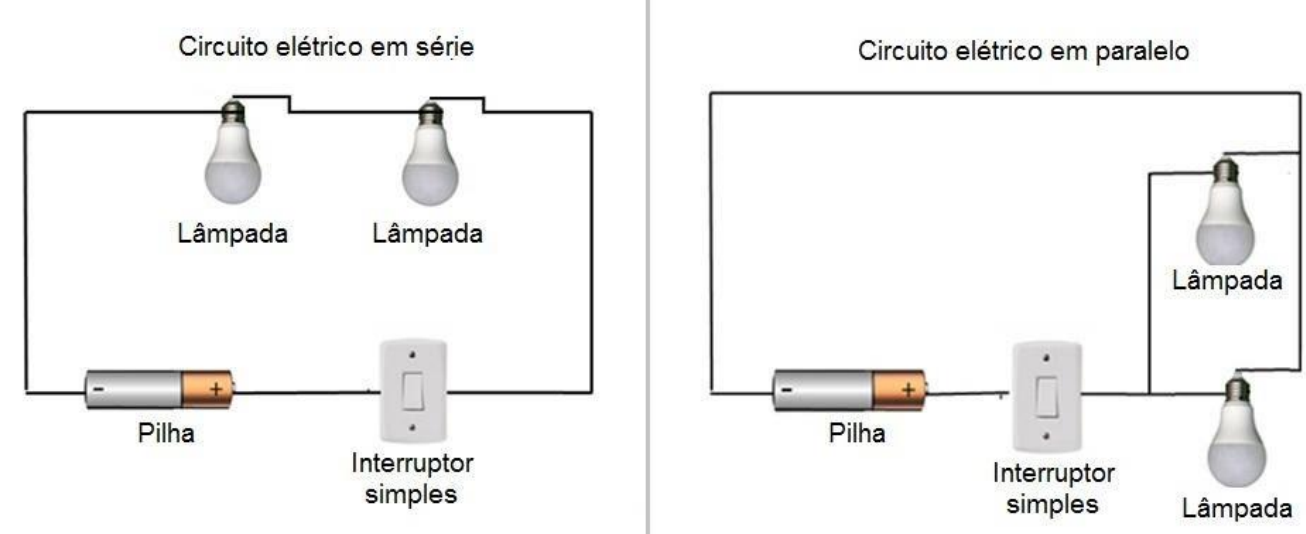

Fonte: O autor (2020).

Posteriormente, no laboratório de informática, o professor apresentou aos alunos componentes animados que simulavam o funcionamento dos interruptores paralelos e intermediários (Figuras 3 e 4).

Figura 3 - Representação e funcionamento dos interruptores paralelos por meio de interfaces animadas e interativas

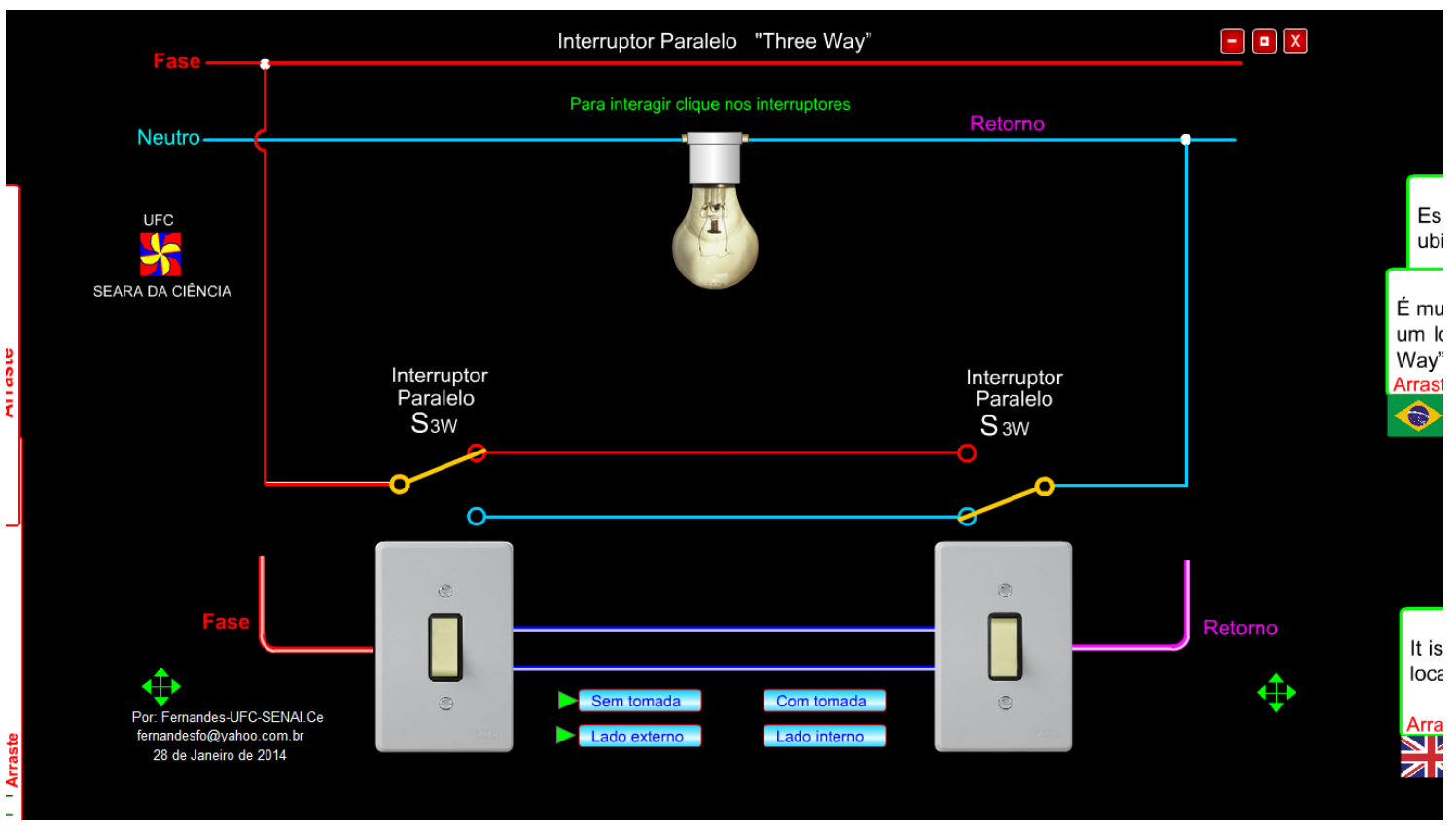

Fonte: OLIVEIRA (2014). 
Figura 4 - Representação e funcionamento do interruptor intermediário por meio de interfaces animadas e interativas

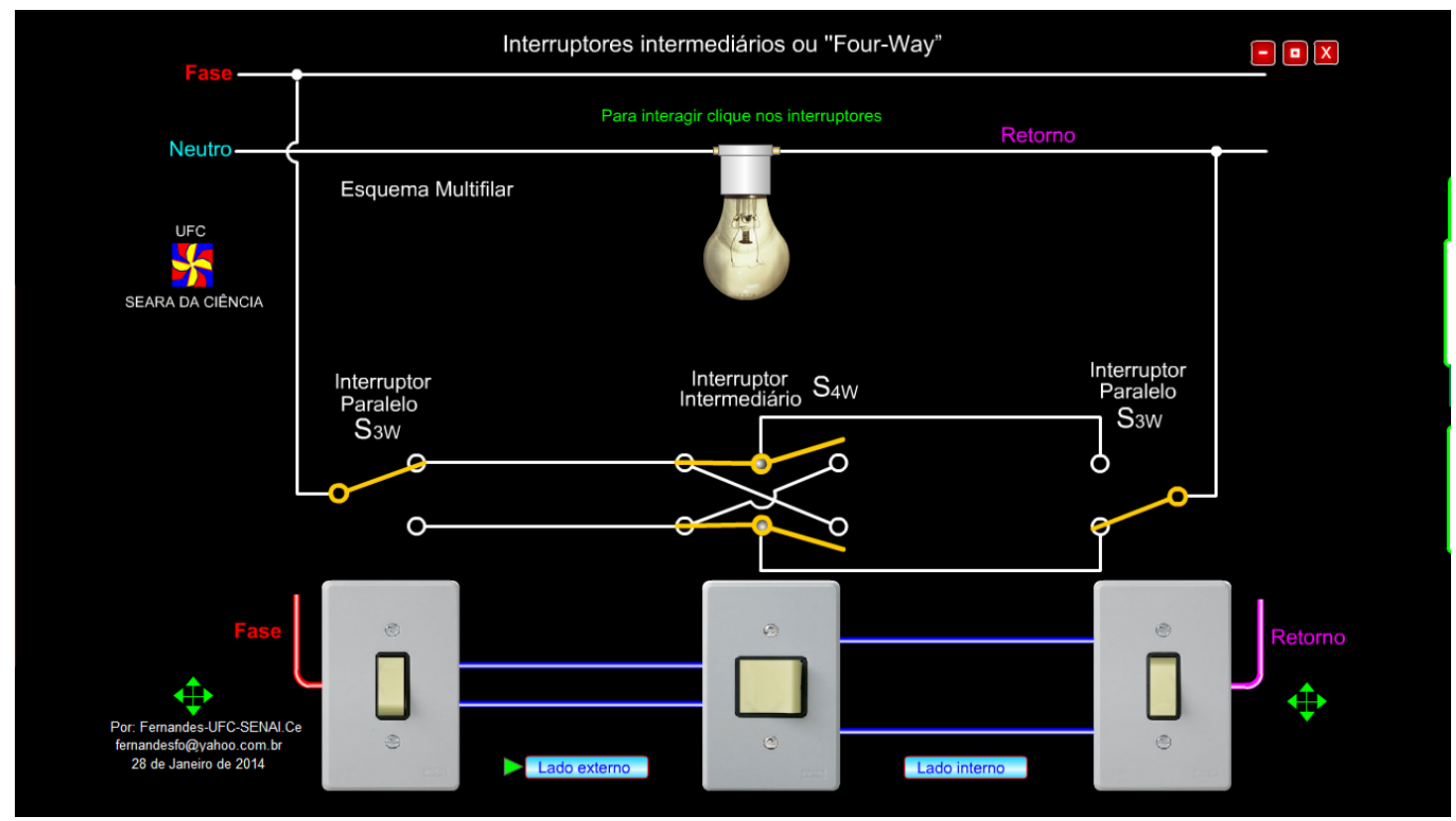

Fonte: OLIVEIRA (2014).

Estes componentes animados, cedidos gratuitamente para esta pesquisa, foram elaborados pelo professor Raimundo Fernandes de Oliveira com apoio da Universidade Federal do Ceará (UFC), são interativos e permitem que alunos modifiquem o funcionamento do circuito de iluminação para verificar o que ocorre com a lâmpada, que pode ficar acessa ou apagada dependendo da configuração do circuito. Essas tecnologias são ferramentas pedagógicas que propiciam ao aluno mais autonomia no seu processo de aprendizagem, estimulando atitudes mais ativas. Vale ressaltar que os alunos participantes desta pesquisa possuem familiaridade com o uso de tecnologias digitais, o que facilitou a implementação destas tecnologias no ensino.

A aula prática foi dividida em duas atividades, cada uma valendo cinco pontos. Inicialmente os alunos receberam orientações sobre a correta utilização dos equipamentos e informações referentes as normas de segurança adotadas no Laboratório de Instalações Elétricas. O planejamento pedagógico elaborado nesta etapa tinha como objetivo permitir a montagem de circuitos elétricos reais utilizando interruptores simples, intermediários e paralelos a partir dos componentes que fazem parte destes sistemas. A primeira atividade consistia na montagem de um circuito de iluminação com interruptor simples e a segunda etapa na montagem de um circuito de iluminação com interruptor intermediário, conforme mostrado na Figura 5. Caso a montagem estivesse correta, a lâmpada funcionava, e o aluno ganhava cinco pontos, mas se a montagem estivesse errada a pontuação era nula. Para a realização da atividade, foi colocado na bancada do laboratório três modelos de interruptores (simples, paralelo e 
intermediário) de modo que o aluno deveria selecionar o interruptor mais adequado para a montagem de casa circuito proposto.

Figura 5 - Atividade prática para montagem do sistema de iluminação utilizando interruptor intermediário, realizada no Laboratório de Instalações Elétricas do IFMG
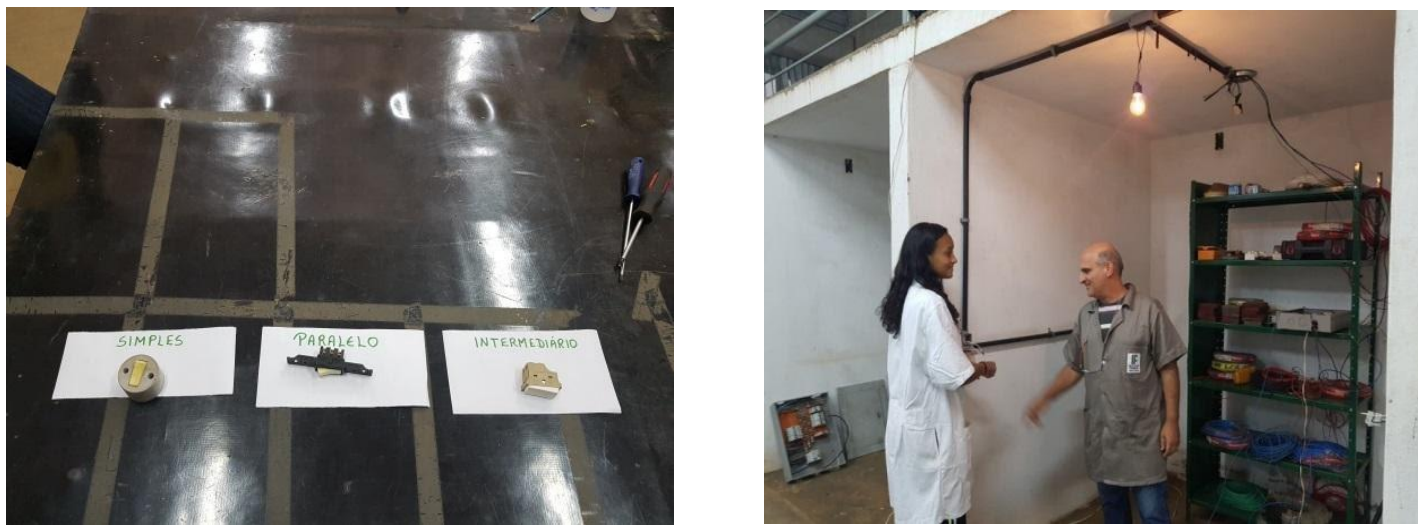

Fonte: O autor (2020).

A seguir, serão apresentados os resultados das avaliações e da entrevista semiestruturada realizada com os alunos participantes desta pesquisa.

\section{Resultados e Discussões}

A Tabela 1 apresenta a pontuação obtida pelos alunos nos testes e na aula prática realizada no Laboratório de Instalações Elétricas. Em relação à pontuação obtida no Teste 2 , se o aluno realizasse a montagem de um dos circuitos de forma correta, recebia pontuação máxima de cinco pontos, caso contrário o valor obtido seria zero. A progressão representa a relação entre a diferença de pontuação entre o Teste Final e Inicial pelo valor do Teste Inicial. O valor positivo indica que houve progressão do aluno, ou seja, seu desempenho para resolução das questões foi melhor. Neste caso, pode ser um indicativo de que houve assimilação do conteúdo pelo aluno. Já os valores negativos indicam que o desempenho do aluno na avaliação diagnóstica piorou.

Tabela 1 - Resultado das atividades avaliativas realizadas pelos alunos

\begin{tabular}{c|c|c|c|c|c}
\hline \multirow{2}{*}{ Aluno } & \multicolumn{4}{|c|}{ Notas } & \multirow{2}{*}{$\begin{array}{c}\text { Progressão } \\
\text { (\%) }\end{array}$} \\
\cline { 2 - 5 } & $\begin{array}{c}\text { Teste } \\
\mathbf{1}\end{array}$ & $\begin{array}{c}\text { Teste } \\
\mathbf{2}\end{array}$ & $\begin{array}{c}\text { Teste } \\
\mathbf{3}\end{array}$ & $\begin{array}{c}\text { Aula } \\
\text { Prática }\end{array}$ & \\
\hline 1 & 4,78 & 10 & 7,39 & 10 & 54,6 \\
\hline
\end{tabular}




\begin{tabular}{c|c|c|c|c|c}
\hline 2 & 7,83 & 10 & 10,0 & 10 & 27,7 \\
\hline 3 & 2,61 & 10 & 8,7 & 0 & 233,3 \\
\hline 4 & 4,35 & 5 & 7,83 & 5 & 80,0 \\
\hline 5 & 5,22 & 10 & 7,83 & 5 & 50,0 \\
\hline 6 & 5,65 & 10 & 6,09 & 10 & 7,8 \\
\hline 7 & 4,78 & 10 & 8,7 & 10 & 82,0 \\
\hline 8 & 4,78 & 10 & 9,57 & 10 & 100,2 \\
\hline 9 & 3,91 & 10 & 8,26 & 10 & 111,3 \\
\hline 10 & 8,26 & 10 & 7,83 & 5 & $-5,2$ \\
\hline 11 & 6,52 & 10 & 9,57 & 10 & 46,8 \\
\hline 12 & 4,35 & 10 & 7,83 & 5 & 80,0 \\
\hline 13 & 5,65 & 10 & 7,83 & 10 & 38,6 \\
\hline 14 & 15,0 & 10 & 6,52 & 10 & $-56,5$ \\
\hline 15 & 6,52 & 10 & 6,96 & 5 & 6,7 \\
\hline 16 & 6,09 & 10 & 7,83 & 10 & 28,6 \\
\hline 17 & 6,96 & 10 & 6,52 & 5 & $-6,3$ \\
\hline 18 & 7,83 & 10 & 10,0 & 5 & 27,7 \\
\hline
\end{tabular}

Fonte: O autor (2020).

Como já era esperada, a maior parte dos alunos (55,6 \%) tiveram notas abaixo de 6,0 pontos no Teste 1, considerada a média para um bom desempenho. Este resultado pode ser explicado pelo fato deste teste ter sido aplicado antes da apresentação do conteúdo e aplicação da SD aos alunos. Ou seja, os alunos tinham inicialmente uma percepção vaga sobre o funcionamento de um sistema de iluminação residencial acionado por interruptores. É importante destacar que antes de iniciar esta pesquisa, estes alunos aprenderam conceitos relativos a eletromagnetismo na disciplina de Física.

As notas obtidas no Teste 2 demonstram que quase a totalidade dos alunos conseguiram assimilar o conteúdo abordado nas Aulas 2 e 3, sobre o funcionamento de circuitos elétricos em série e em paralelo. Apenas um aluno não conseguiu realizar a montagem do circuito em paralelo no Laboratório de Informática. Durante as aulas, foi observado a facilidade e domínio de utilização do software PhET pelos alunos. Essa abordagem pedagógica utilizada no Teste 2 está em consonância com as ideias de Cabral (2017) que enfatiza a necessidade de o aluno ser mais ativo e participativo no seu processo de aprendizagem, o que pode explicar o bom desempenho dos alunos nesta fase da SD.

Em relação às atividades feitas no Laboratório de Instalações Elétricas (Aula 5), aproximadamente $55,6 \%$ dos alunos conseguiram montar de forma correta os sistemas de iluminação residencial utilizando interruptores simples, paralelos e intermediários. Apenas um aluno não conseguiu realizar a montagem dos dois sistemas de iluminação avaliados na aula prática. 
Podemos afirmar pelos resultados apresentados nos Testes 1 e 3 que aproximadamente $83 \%$ dos alunos que participaram da pesquisa apresentaram progressão na aprendizagem do tema. Ou seja, tiveram uma melhor compreensão do funcionamento dos interruptores de luz em uma edificação, visto que as notas obtidas no Teste 3 , para estes alunos, foram maiores que aquelas incialmente obtidas no Teste 1. Portanto, a SD utilizada nesta pesquisa mostra-se adaptada ao perfil dos alunos participantes, visto que são predominantemente sensoriais, visuais e ativos, contribuindo para tornar 0 processo de ensino-aprendizagem mais eficiente, segundo relatado por Pereira e Vieira (2013) em suas pesquisas.

Três alunos apresentaram ao final do processo um desempenho insatisfatório referente à assimilação do conteúdo abordado na SD, visto que suas notas no Teste 3 foram piores que aquelas obtidas no Teste 1. Dois destes alunos concluíram o ensino fundamental escolas públicas e possuem renda familiar menor que um salário mínimo. Vale destacar que, a aluna 17, é uma aluna portadora de surdez de nascença e seu baixo rendimento no Teste 3 pode estar associado as estratégias pedagógicas adotadas na SD, que possivelmente foram pouco eficientes ou mal adaptadas quando se trata de alunos com este tipo de deficiência auditiva.

A fim de avaliar a percepção dos alunos sobre a sequência didática utilizada, foram selecionados nove alunos para uma entrevista semiestruturada. A seleção destes alunos foi feita mediante aos resultados mais significativos obtidos nos Testes 1 e 3, ou seja, alunos com maiores e menores índices de progressão. No Quadro 3 estão resumidas as respostas obtidas.

Pode-se observar que a SD melhorou a compreensão destes alunos sobre $o$ assunto abordado. Foi unânime a opinião de que a sequência didática os auxiliou a compreender melhor o conteúdo, e a maioria sentiu-se mais motivado com a montagem física no laboratório de Instalações Elétricas, mesmo em comparação com a simulação pelo software PhET, surpreendentemente. Foi constatado pelas respostas dadas que os alunos preferem aprendizado ativo, visto que a maioria apresentou mais dificuldades de aprendizado na aula expositiva convencional. Considerada por eles como a fase mais difícil para o processo de aprendizagem. Fica evidente que estas aulas tradicionalistas, onde o professor normalmente inibe a postura ativa do aluno no processo de ensinoaprendizagem pode contribuir de forma negativa na motivação do aluno pelo conteúdo ensinado. Freire (1987) já assinalava a importância de adaptar as práticas pedagógicas de forma que o aluno seja o protagonista no processo de aquisição do conhecimento. 
Quadro 3 - Avaliação da SD feita por alguns alunos durante a entrevista semiestruturada

\begin{tabular}{|c|c|c|c|c|}
\hline \multirow{2}{*}{ Aluno } & \multicolumn{3}{|c|}{ Perguntas e respostas obtidas na entrevista semiestruturada } \\
\cline { 2 - 5 } & $\begin{array}{c}\text { A SD contribuiu } \\
\text { para assimilar o } \\
\text { conteúdo em } \\
\text { comparação com } \\
\text { uma aula } \\
\text { convencional? }\end{array}$ & $\begin{array}{c}\text { Qual fase da } \\
\text { SD você teve } \\
\text { mais } \\
\text { dificuldade } \\
\text { para } \\
\text { assimilar? }\end{array}$ & $\begin{array}{c}\text { Qual das fases Ihe } \\
\text { causou mais } \\
\text { motivação para } \\
\text { o aprendizado? }\end{array}$ & $\begin{array}{c}\text { Após } \\
\text { participar da } \\
\text { pesquisa, o } \\
\text { seu interesse } \\
\text { pelo tema: }\end{array}$ \\
\hline 1 & Sim & Aula expositiva & Aula prática & Aumentou \\
\hline 3 & $\operatorname{Sim}$ & Aula prática & Aula prática & $\begin{array}{c}\text { Permaneceu o } \\
\text { mesmo }\end{array}$ \\
\hline 6 & $\operatorname{Sim}$ & $\begin{array}{c}\text { Utilização do } \\
\text { PhET }\end{array}$ & Aula prática & $\begin{array}{c}\text { Permaneceu o } \\
\text { mesmo }\end{array}$ \\
\hline 7 & Aula prática & Utilização do PhET & $\begin{array}{c}\text { Permaneceu o } \\
\text { mesmo }\end{array}$ \\
\hline 8 & $\operatorname{Sim}$ & Nenhuma & Aula expositiva & $\begin{array}{c}\text { Permaneceu o } \\
\text { mesmo }\end{array}$ \\
\hline 9 & $\operatorname{Sim}$ & Aula expositiva & Aula prática & Aumentou \\
\hline 10 & $\operatorname{Sim}$ & Aula prática & Aula prática & $\begin{array}{c}\text { Permaneceu o } \\
\text { mesmo }\end{array}$ \\
\hline 14 & $\operatorname{Sim}$ & Aula expositiva & Aula prática & $\begin{array}{c}\text { Permaneceu o } \\
\text { mesmo }\end{array}$ \\
\hline 17 & $\operatorname{Sim}$ & Aula expositiva & Aula prática & Aumentou \\
\hline
\end{tabular}

Fonte: O autor (2020).

Em relação à aluna com deficiência auditiva, mesmo que a SD tenha contribuído para aumentar o interesse pelo tema, é necessário adaptar melhor as práticas pedagógicas adotadas, visto que a aluna não obteve progressão, se comparado as pontuações obtidas nos Testes 1 e 3. Apesar dos alunos 10, 14 e 17 apresentarem resultados de progressão insatisfatórios, relataram na entrevista que a SD contribuiu para melhor compreensão sobre o tema. Neste caso, seria necessária uma avaliação mais criteriosa com estes alunos para verificar os resultados discordantes entre a progressão e a respostas da entrevista.

De acordo com a Quadro 3, a fase mais motivadora para aprendizagem do tema foi a aula prática realizada no Laboratório de Instalações Elétricas do IFMG, pois nesta etapa os alunos foram desafiados a colocar em prática todo o conteúdo adquirido sobre o sistema de iluminação residencial. Além disso, nesta etapa eles passaram a ter contato com os componentes reais dos circuitos elétricos e observam seu funcionamento numa perspectiva mais científica devido ao conhecimento obtido durante a aplicação da SD.

\section{Conclusões}


Pode-se concluir que o uso da SD, quando bem planejada, torna 0 processo de ensino-aprendizagem mais dinâmico, interativo e mais eficiente. Para tanto, é necessário definir bem as estratégias pedagógicas utilizadas, de forma que o professor consiga ensinar o conteúdo com mais eficiência. Aulas tradicionalistas, baseadas apenas na exposição oral do professor com aplicação de exercícios exemplificativos dentro da sala de aula podem ser desmotivadoras para a maioria dos alunos, conforme apontado na entrevista realizada nesta pesquisa. Em relação ao ensino do funcionamento de interruptores nos circuito elétricos residenciais é interessante variar as ferramentas pedagógicas adotadas, principalmente com atividades práticas laboratoriais que propiciam maior interesse dos alunos pelo tema proposto. O grande desafio do docente é conseguir relacionar o conteúdo abordado na aula com a realidade vivenciada pelos alunos no cotidiano.

O uso de tecnologias no ensino contribui para melhor assimilação do tema proposto na SD, quando utilizadas de forma planejada e adaptada, como foi o caso desta pesquisa, que utilizou o software PhET e os componentes animados. Essas ferramentas colaboram para o aluno ter uma postura mais independente e ativo no seu processo de aprendizagem, além de estimular o desenvolvimento de novas habilidades. Entretanto, para adotar estas ferramentas pedagógicas, é necessário que o espaço físico escolar forneça infraestrutura adequada e computadores em quantidade suficiente para atender a todos os alunos. Para tanto, Lopes et al. (2016) recomenda uma reforma pedagógica que envolva os professores, alunos e o sistema educacional, de forma a adaptar o ambiente escolar as novas tecnologias digitais utilizadas pela geração atual.

Fica evidente, pelas respostas fornecidas pelos alunos entrevistados que as aulas práticas para a montagem real dos circuitos elétricos são fundamentais para motivar os alunos na compreensão do tema. Recomenda-se que sempre que possível, os cursos Técnicos em Edificações utilizem as aulas práticas laboratoriais durante o ensino de execução de projetos elétricos para fins residenciais. Pois conforme apontado por Pereira e Vieira (2013), alunos do ensino médio lembram daquilo que veem por imagens e demonstrações. Além disso, devemos ressaltar que os alunos são receptivos as atividades que envolvem resolução de problemas práticos, pois desafia os mesmos a utilizar os conhecimentos adquiridos previamente.

\section{REFERÊNCIAS}

BRASIL. Parâmetros Curriculares Nacionais: primeiro e segundo ciclos do Ensino Fundamental- Língua Portuguesa. Ministério da Educação. Brasília. 1997.

BORGES, Maria de Lourdes; SILVA, Adelina G. da. Implicações de um Cenário Multigeracional no Ambiente de Trabalho: Diferenças, Desafios e Aprendizagem. In: IV 
Encontro de gestão de Pessoas e Relações de Trabalho. Disponível em: http://www.anpad.org.br/admin/pdf/EnGPR250.pdf. Acesso em: 30 mar. 2020.

CABRAL, N. F. Sequências Didáticas: Estrutura e elaboração. Belém: SBEM, 2017.

COVOLAN, S. C. T.; SILVA, D. Ciência \& Educação, v. 11, n. 1, p. 98-117, 2005.

DOLZ, J.; NOVERRAZ, M.; SCHNEUWLY, B. Sequências didáticas para o oral e a escrita. Campinas: Mercado das Letras, 2004.

FELDER, R. M.; SILVERMAN, L. K. Learning and teaching styles in engineering education. Journal of Engineering Education, Washington, v. 7, n. 78, p. 674-681, 1988.Disponível em: https://www.engr.ncsu.edu/wpcontent/uploads/drive/1QP6kBI1iQmpQbTXL-08HSI0PwJ5BYnZW/1988-LS-plusnote.pdf. Acesso em: 24 set. 2019.

FREIRE, P. Pedagogia do oprimido. 17. ed. Rio de Janeiro: Paz e Terra, 1987.

LARA, L. A. M. Instalações Elétricas. Ouro Preto: IFMG, 2016.

LOPES, R.T.; PEREIRA, Andresa Costa; Silva, Marco Antônio Dias da. Análise Comparativa da Familiaridade e Uso das TIC por Alunos de Odontologia. Revista Brasileira de Educação Médica, № 40, p. 254-260, 2016. Disponível em: http://www.scielo.br/pdf/rbem/v40n2/1981-5271-rbem-40-2-0254.pdf. Acesso em: 18 Mar. 2020.

MOREIRA, M.A. Modelos Mentais. Em: Faculdade de Educação da UFMG (Org.), In: Encontro Sobre Teoria e Pesquisa em Ensino de Ciência, I., 1997, Belo Horizonte, MG. Anais. Belo Horizonte: Faculdade de Educação, UFMG.

NISKIER, J.; MACINTYRE, A. J. Instalações Elétricas. 6a. ed. Rio de Janeiro: LTC, 2016.

OLIVEIRA, F. Componentes animados sobre funcionamento de interruptores. Contato pessoal. 2019.

OLIVEIRA, M. M. Sequência didática interativa no processo de formação de professores. Petrópolis: Vozes, 2013.

PEREIRA, E. J.; JUNIOR, N. V. Os Estilos de Aprendizagem no Ensino Médio a partir do Novo ILS e a Sua Influência na Disciplina de Matemática. Alexandria, Florianópolis, v.6, n.3, p.173-190, nov. 2013.

PhET. Kit para montar circuito DC. Disponível em:

https://phet.colorado.edu/sims/html/circuit-construction-kit-dc/latest/circuit-constructionkit-dc_pt_BR.html. Acesso em: 18 set. 2019.

VÁLIO, A. B. M. et al. Fisica. São Paulo: Edições SM, 2016.

VIEIRA JUNIOR, N.; COLVARA, L. D. Os modelos mentais de alunos em relação a vetores em duas e três dimensões: uma análise da dinâmica da aprendizagem e da 
inadequação das avaliações tradicionais. Revista Ciências \& Cognição, Rio de Janeiro, v. 15, n. 2, p. 55- 69, 2010.

VIEIRA JÚNIOR, Niltom. Planejamento de um ambiente virtual de aprendizagem baseado em interfaces dinâmicas e uma aplicação ao estudo de potência elétrica. 2012. Tese (Doutorado em Engenharia Elétrica) - Faculdade de Engenharia de Ilha Solteira, Universidade Estadual Paulista, UNESP, Ilha Solteira, 2012.

ZABALA, A. A prática educativa: como ensinar. Porto Alegre: Artmed, 1998. 